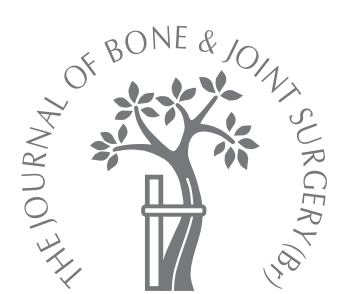

B. M. Wroblewski, P. D. Siney, P. A. Fleming

From The John Charnley Research Institute, Wrightington Hospital, Wigan, England

\title{
Charnley low-friction arthroplasty
}

\author{
SURVIVAL PATTERNS TO 38 YEARS
}

\begin{abstract}
We studied survival to 38 years after Charnley low-friction arthroplasty of the hip. We used revision as an end-point, while adopting a policy of regular follow-up and early revision for radiological changes alone if indicated.
\end{abstract}

Between November 1962 and June 2005, 22066 primary low-friction arthroplasties (17 409 patients) had been performed at Wrightington Hospital by more than $\mathbf{3 3 0}$ surgeons. By June 2006, 1001 (4.5\%) hips had been revised and 1490 patients (2662 hips, 12\%) had died. At $\mathbf{3 1}$ years, where a minimum of $\mathbf{4 0}$ hips were still attending follow-up, survival with revision for infection as an endpoint was $\mathbf{9 5 \%}$, for dislocation $\mathbf{9 8 \%}$, for a fractured stem $\mathbf{8 8 . 6} \%$, for a loose stem $\mathbf{7 2 . 5 \%}$ and for a loose acetabular component $\mathbf{5 3 . 7 \%}$. Wear and loosening of the ultra-high-molecular-weight polyethylene acetabular component were the main long-term problems.

We conclude that regular follow-up after hip replacement is essential and that all operative findings should be recorded at revision.

The use of survival analysis, ${ }^{1}$ within the limits suggested by Lettin, Ware and Morris, ${ }^{2}$ offers uniformity of terminology and comparability of results, which are essential features of scientific communication. The Swedish National Total Hip Arthroplasty Register ${ }^{3}$ has set clear standards, with revision total hip replacement (THR) as the end-point. However, the timing of a revision will influence the pattern of survival analysis. Revisions early in a series, either because of a specific indication or because of an established clinical practice, ${ }^{4}$ will have little effect on the cumulative rate of success if large numbers of THRs are involved. Conversely, with increasing followup, as the number of THRs at risk declines and the number of failures increases, so each revision will have a greater negative effect on survival. As clinical results do not reflect the mechanical state of a THR, ${ }^{5}$ to await symptoms implies that revisions are likely to be performed late. If this happens then the incidence and complexity of complications may increase. Furthermore, if records do not include the operative findings, the available information is of limited value. Soderman, ${ }^{6}$ validating the results of the Swedish Register, summarised this point succinctly: "the results ... with revision as failure end-point give an exact but limited information about the quality of hip replacement in Sweden ... the rate of combined clinical and radiographic failure was at least twice as high as the register presents in survivorship analysis." We have examined the survival after primary Charnley low-friction arthroplasty (LFA) (DePuy International, Leeds, United Kingdom) with revision as the end-point, and documented all the operative findings.

\section{Patients and Methods}

We examined our database to obtain information on the patients who had undergone primary LFA, including their follow-up and any revisions. The details of the findings at revision THR were documented under the headings of infection, dislocation, a fractured or loose stem, or a loose acetabular component. The number of findings was therefore greater than the number of LFAs revised, and the information gathered more valuable than simply recording a single indication for revision. Our policy is one of regular follow-up and early revision, if need be for radiological changes alone, ${ }^{4}$ unless there are serious contraindications. Routine follow-up was at three months post-operatively and then annually. However, with increasing follow-up and experience it was possible to individually tailor the review according to the radiological appearances of an $\mathrm{LFA}^{7,8}$ the level of activity ${ }^{9}$ and the rate of acetabular component penetration. ${ }^{10}$ Patients 
Table I. Underlying pathology for all hips in this study (22 066)

\begin{tabular}{lc}
\hline Diagnosis & Number of hips ${ }^{*}$ (\%) \\
\hline Primary osteoarthritis & $14468(65.6)$ \\
& \\
Secondary arthritis & $1448(6.6)$ \\
$\quad$ Congenital dislocation, dysplasia, subluxation & $990(4.5)$ \\
$\quad$ Avascular necrosis of the femoral head & $804(3.6)$ \\
$\quad$ Trauma (including fracture of the neck of the femur) & $314(1.4)$ \\
$\quad$ Slipped upper femoral epiphysis & $202(0.9)$ \\
$\quad$ Perthes' disease & $1929(8.7)$ \\
Rheumatoid arthritis/Still's disease & $1851(8.4)$ \\
& \\
Idiopathic protrusio & $361(1.6)$ \\
Paget's disease & $246(1.1)$ \\
Ankylosing spondylitis & \\
Sepsis & $156(0.7)$ \\
Acute & $72(0.3)$ \\
Chronic &
\end{tabular}

Table II. Previous operative procedures

\begin{tabular}{ll}
\hline Procedure & Number of hips (\%) \\
\hline Femoral/pelvic osteotomy & $1150(5.2)$ \\
$\begin{array}{l}\text { Open reduction of developmental dys- } \\
\text { plasia of the hip and internal fixation }\end{array}$ & $302(1.4)$ \\
Fusion/attempted fusion of the hip & $159(0.7)$ \\
\hline
\end{tabular}

with no symptoms and no radiological changes were given a maximum of four years until their next follow-up, whereas those with symptoms or radiological changes would have a shorter follow-up at between six months and one year.

\section{Results}

Between November 1962 and June 2005, 22066 primary Charnley LFAs were performed at Wrightington Hospital on 17409 patients, 4657 (27\%) of whom had bilateral procedures. The mean age of the patients' was 67 years (12 to 93). The underlying pathology is shown in Table I, and the number of previous operations on the hips in Table II. At the time of analysis in June 2006, 1001 LFAs (45\%) were known to have been revised and 1490 patients (2662 hips, $12 \%)$ had died. The findings at revision are shown in Table III. At 31 years, with a minimum of 40 hips still attending follow-up, survival with revision as the end-point, but also documenting operative findings, was for infection $95 \%$, for dislocation $98 \%$, for a fractured stem $88.6 \%$, for a loose stem $72.5 \%$, for a loose acetabular component $53.7 \%$.

Survival, with revision for individual complications as the end-point is shown as a composite graph in Figure 1.
Table III. Indications and findings at revision

\begin{tabular}{|c|c|}
\hline Findings at revision & Number of hips (\%) \\
\hline Infection & $249(1.13)$ \\
\hline Dislocation & $55(0.25)$ \\
\hline Loose acetabular component & $218(0.99)$ \\
\hline Loose stem & $113(0.51)$ \\
\hline Loose acetabular component and stem & $147(0.67)$ \\
\hline Fractured stem & $146(0.66)$ \\
\hline $\begin{array}{l}\text { Loose acetabular component and } \\
\text { fractured stem }\end{array}$ & $38(0.17)$ \\
\hline Unexplained pain & $16(0.07)$ \\
\hline $\begin{array}{l}\text { Loose acetabular component and } \\
\text { dislocation }\end{array}$ & $8(0.04)$ \\
\hline \multicolumn{2}{|l|}{ Fractured } \\
\hline Femur & $6(0.03)$ \\
\hline Acetabular component & $4(0.02)$ \\
\hline Loose stem and dislocation & $1(0.005)$ \\
\hline Total & 1001 \\
\hline
\end{tabular}

Survival with revision for all complications was $30 \%$ at 31 years.

\section{Discussion}

Survival analysis, with each operation being assigned to the same starting point, is an accepted method of reporting the results of THR. Revision, for any indication, is usually taken as the end-point. We have not done this, but have 


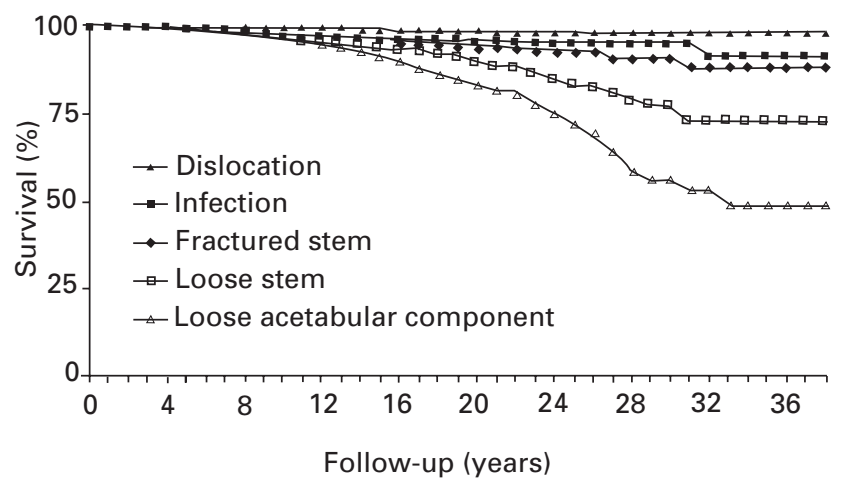

Fig. 1

Survivorship analysis with findings at revision as the end-point.

reported our revision rates with different clinical indications and findings at revision as end-points.

The consistency of the Charnley concept applied to clinical practice has been invaluable, not only in constructing meaningful survival tables, but also in offering sound ideas for further development.

We found that deep infection was an early problem, with $59 \%$ (147 of 249 ) being revised within the first four years and $82.7 \%$ (206 of 249 ) by nine years. Late haematogenous infection was infrequently encountered and is the subject of an ongoing study.

Episodes of subluxation and even dislocation, with spontaneous reduction, may pass unrecorded; the incidence will thus be under-reported.

Revision for recurrent or persistent dislocation should not present such a difficulty. The very low incidence of revisions for dislocation $(0.22 \%)$ in our study, together with others, ${ }^{11,12}$ which report similarly low rates of revision for dislocation using a small femoral head, clearly suggests that the small head of the Charnley LFA does not carry a high risk of dislocation. Fracture of the original flat back stem was once a common indication for revision. However, the introduction of high-nitrogen stainless steel Ortron (DePuy International, Leeds, United Kingdom), as well as improved cementing techniques, ${ }^{13,14}$ have eliminated the problem.

Revisions for aseptic stem loosening, performed between two and four years after primary surgery (18 hips, 6.9\%), can probably be attributed to inadequate operative technique.

However, with improved cementing, endosteal cavitation of the femur and loosening of the stem did not become a problem until more than 11 years after primary THR. ${ }^{14}$ These changes appear when the incidence of stem fracture has passed its peak. The triple-tapered polished stem - the C-stem (DePuy International) and avoidance of distal stem support ${ }^{15}$ are expected to offer long-term benefits in this respect by reducing the loss of proximal support seen so often.
Wear and loosening of an ultra-high-molecular-weight polyethylene (UHMWPE) acetabular component is a significant long-term problem. Revisions within the first five years may sometimes be attributed to operative technique. However, after the fifth year, wear of the acetabular component, measured as penetration and leading to loosening, becomes an increasing problem; $72.6 \%$ are revised between the seventh and the 20th years. Thereafter, the incidence of revisions declines: $16.6 \%$ between the 21 st and 28 th years.

Declining activity levels, reduced rates of wear and the decision not to undertake a revision for an asymptomatic non-progressive loosening must also be taken into account when presenting revision, as opposed to radiological failure, as the end point.

Occasionally, wearing of the UHMWPE acetabular component may result in fracture of the component remnant but without loosening. ${ }^{16}$ There were four such cases in our series.

Our principle of regular follow-up and early revision, if need be for radiological changes alone, is an integral part of informed consent for primary surgery. As clinical results do not always reflect the mechanical state of an arthroplasty, ${ }^{4}$ to delay an inevitable revision will lead to progressive loss of bone stock, more complex technical problems, and loss of the opportunity to achieve a better outcome. In addition, the recording of all findings at revision is essential if the information is to be of subsequent value. Other than endosteal cavitation and loosening of the stem, wear and loosening of the UHMWPE acetabular component is a significant long-term problem. It is here that ceramics and cross-linked polyethylene ${ }^{17}$ may have a part to play.

In this study the difference between the number of LFAs revised and the number of operative findings was $17.8 \%$ (1001 revisions; 1178 indications for revision). This suggests that revisions, as reported to the Swedish National Total Hip Arthroplasty Register, are undertaken late, but also implies that the Register does indeed give 'exact but limited information', ${ }^{6}$ and may therefore not achieve some of the aims for which it was created. If the same method of reporting is used by other joint registers, ${ }^{18}$ a similar criticism would also apply.

Research supported by the Peter Kershaw and John Charnley Trusts. We would like to acknowledge all the surgeons at Wrightington Hospital whose records are used in this paper, and to help from the Office of National Statistics in Southport.

No benefits in any form have been received or will be received from a commercial party related directly or indirectly to the subject of this article.

\section{Supplementary Material}

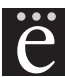
Additional tables showing survival analyses and confidence limits are available with the electronic version of this article on our website at www.jbjs.org.uk

\section{References}

1. Kaplan EL, Meier P. Nonparametric estimation from incomplete observations. J Am State Assoc 1958;53:457-81.

2. Lettin AF, Ware HS, Morris RW. Survivorship analysis and confidence intervals: an assessment with reference to the Stanmore total knee replacement. J Bone Joint Surg [Br] 1991;73-B:729-31. 
3. Ahnfelt L. Re-operade totalahoftledsplastiker i Sverige under aren 1979-1983 Thesis Goteborg University. Goteborf Sweden, 1986.

4. Wroblewski BM, Siney PD, Fleming PA. Charnley low frictional torque arthroplasty in patients under the age of 51 years: follow-up to 33 years. J Bone Joint Surg [Br] 2002;84-B:540-3.

5. Wroblewski BM, Fleming PA, Siney PD. Charnley low-frictional torque arthroplasty of the hip: 20 to 30 year results. J Bone Joint Surg [Br] 1999;81-B:427-9.

6. Soderman P. On the validity of the results from the Swedish National Total Hip Arthroplasty Register. Acta Orthop Scand Supp/ 2000;71:4-33.

7. Pacheco V, Shelley P, Wroblewski BM. Mechanical loosening of the stem in Charnley arthroplasties: indentification of the "at risk" factors. J Bone Joint Surg [Br]1988;70-B:596-9.

8. Hodgkinson JP, Shelley P, Wroblewski BM. The correlation between roentgenographic appearance and operative findings at the bone-cement junction of the socket in the Charnley Iw-friction arthroplasties. Clin Orthop 1988;228:105-9.

9. Feller JA, Kay PR, Hodgkinson JP, Wroblewski BM. Activity and socket wear in the Charnley low-friction arthroplasty. J Arthroplasty 1994;9:341-5.

10. Wroblewski BM. Charnley low-friction arthroplasty in patients under the age of 40 years. In: Sevastik J, Goldie I, eds. The young patient with degenerative hip disease. Stockholm: Almquist and Wiksell, 1985:197-201.

11. Berry DJ, Harmsen WD, Cabanela ME, Morrey BF. Twenty-five-year survivorship of two thousand consecutive primary Charnley total hip replacements: factors affecting survivorship of acetabular and femoral components. J Bone Joint Surg [Am]2002;84-A:171-7.
12. Schulte KR, Calaghan JJ, Kelley SS, Johnston RC. The outcome of Charnley total hip arthroplasty with cement after a minimum twenty year follow-up: the results of one surgeon. J Bone Joint Surg [Am] 1993;75-A:961-75

13. Wroblewski BM, van der Ritj AJ. Intramedullary cancellous bone block to improve femoral stem fixation in the Charnley low-friction arthroplasty. J Bone Joint Surg [Br] 1984;66-B:639-44.

14. Wroblewski BM, Fleming PA, Hall RM, Siney PD. Stem fixation in the Charnley low-friction arthroplasty in young patients using an intramedullary bone block. J Bone Joint Surg [Br] 1998;80-B:273-8.

15. Wroblewski BM, Siney PD, Fleming PA. Triple taper polished cemented stem in total hip arthroplasty: rationale for the design, surgical technique, and 7 years of clinical experience. J Arthroplasty 2001;16(Suppl 1):37-41.

16. Wroblewski BM, Siney PD, Fleming PA. Wear and fracture of the acetabular cup in Charnley low friction arthroplasty. J Arthroplasty 1998;13:132-7.

17. Wroblewski BM, Siney PD, Fleming PA. Low friction arthroplasty of the hip using alumina ceramic and cross-linked polyethylene: a 17 year follow-up report. J Bone Joint Surg [Br] 2005;87-B:1220-1.

18. The National Joint Registry (England \& Wales). 1st Annual Report September 2004. www.njrcentre.org.uk/documents/reports/annual/1st/fullreport04.pdf (date last accessed 29 June 2007). 